\title{
Structural Investigation of Concrete and Masonry Structures behind Plaster by means of Pulse Phase Thermography
}

\author{
by R. Arndt*, Ch. Maierhofer*, M. Röllig*, F. Weritz*, H. Wiggenhauser* \\ ${ }^{\star}$ Federal Institute for Material Research and Testing (BAM), Berlin, Germany
}

\begin{abstract}
For non-destructive testing in civil engineering, the application of infrared thermography and especially active approaches as pulse phase thermography have gained more and more importance. Pulse phase thermography is very well suite for the detection of voids and inhomogeneities close to the surface (up to a depth of $10 \mathrm{~cm}$ ) which will be demonstrated in this paper. This method is based on pulse heating of the object under test and on the observation of the cooling down process with an infrared camera. The transient behaviour is afterwards analysed by Fast Fourier Transformation, yielding phase and amplitude images with enhanced visualisation of the defects. Results of European and National (DFG) funded projects are presented.
\end{abstract}

\section{Introduction}

Passive infrared thermography (IRT) has been successfully applied to nondestructive testing (NDT) in civil engineering (CE) in numerous cases. Natural temperature gradients are utilized to reveal heat losses in perimeter walls, sections of moisture or location of wooden framework etc. As a restriction to these applications, an existing temperature gradient is required. And additionally, there are several characteristics that complicate the application of IRT in CE:

1. Building materials in general have relative low thermal conductivities (e.g. concrete compared to metals). This means a very slow response time to temperature changes, hence slow response time for heating up and cooling down processes.

2. Building structures have very large dimensions (e.g. supporting walls compared to plastics and laminates) with deep lying imperfections (like honeycombs in ducts with more than $10 \mathrm{~cm}$ coverage) and are often very hard to access.

3. The outside of buildings, as well as bridges and other traffic constructions, are subject to changing environmental conditions that may have a strong impact on the successful performance of thermographic measurements, e.g. by resulting in non-uniform heating.

4. Existing inhomogeneous surface structures yield to a decreasing signalto-noise ratio.

To overcome the restrictions of passive IRT three active IRT procedures can be applied and have already been further developed for NDT in CE: Lock-in thermography (LT) [1], impulse thermography (IT) [2] and as further improvement of IT pulse phase thermography [3], [4]. These methods have intentionally been developed to investigate laminate structures made of metals and plastics for industrial applications. The application to materials typically used in civil engineering, 
like concrete and masonry structures, requires large modifications of heating tools and parameters.

LT uses a periodical heat wave at a given frequency $\omega$ applied to the object surface. By means of the lock-in technique the thermal response at the same frequency $\omega$ is observed over a series of excitations. The time delay (phase) and to a lesser extent the amplitude of the thermal response is used to extract information about the specimen such as geometry, defect depth, etc. It is also known that phase images deliver information to a greater depth than the corresponding thermal contrast and amplitude images and that the phase is independent of local variations of illumination or of surface emissivity. LT is mainly suited the NDT of thin layered surface structures, the detection of delaminations, impacts, cracks and hidden corrosions in carbon fibre reinforced polymers and metals, e.g. in the inspection of aerospace structures [5]. LT is not suited for most problems related to structural problems that occur in CE. But considering the remission of radiation at selected wavelength has successively been used to detect moisture and imaging moisture distribution at the surface [6].

In IT a high energetic heat pulse is applied to the specimen and the surface temperature is monitored and analysed with an IR sensor (figure 1). Information about delaminations and near surface voids is accumulated through the temperature difference between disturbed and undisturbed areas. Time and amount of the maximum temperature contrast during the cooling down process is used for the detection of defects. In combination with numerical simulations a quantitative proposition e.g. of the thickness of concrete cover is possible [2].

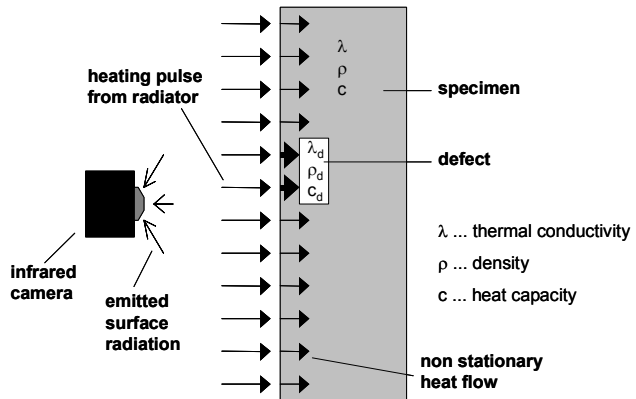

Fig. 1: Principle of impulse thermography.

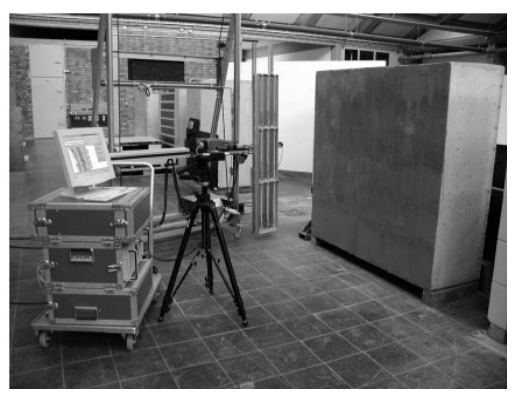

Fig. 2 Experimental set-up for laboratory investigations.

Because of the possibility of high power density of the heat pulse compared to LT, IT is quite useful for NDT in CE [7], [8]. IT delivers solutions for the first and the second of the above mentioned problems by applying an adequate degree of energy and time to the thermographic measurements, the third and the fourth problem however remain.

Often an inhomogeneous surface structure and changing environmental conditions disturb thermographic investigations. To overcome these obstacles PPT, a link between IT and LT that has been established in the recent years [9], has proved to be the adequate tool [10]. With PPT the specimen is pulse heated like in IT. The recorded temperature evolution is processed by performing Fast Fourier Transformation of the time signals. Thus, in addition to the information gained by IT in the time domain, the analysis is performed in the frequency domain like with LT. Amplitude and phase images are than used to extract information about the specimen [10]. 
As a conclusion, PPT combines the advantages of LT and IT and delivers a reduction of the influence of the above mentioned problems of applying IRT in CE.

\section{Experimentals}

At BAM, the applications of IT and PPT so far involve the localisation of voids in concrete structures up to a depth of $10 \mathrm{~cm}$ under ideal conditions, of delaminations of layered structures (e. g. carbon reinforced laminates on concrete) and of delaminations and voids between plaster and concrete or brickwork [7].

The experimental set-up for the performance of IT measurements under laboratory conditions is shown in figure 2. To overcome the above mentioned obstacles of IRT in CE, firstly the scope of time and energy used for a thermographic investigation has to fit to the long response time of the material and the depth of the inhomogeneities. Secondly the used equipment has to be suitable for the geometric and the environmental conditions as well.

Table 1 summarises the experimental set-up parameters for the investigations carried out. It consists of a thermal heating unit, a commercial infrared camera (SC1000) and a computer system which enables digital data recording in real time.

Table 1: Experimental set-up parameters.

\begin{tabular}{|c|c|c|c|c|}
\hline Problem & Location & Heating unit & $\begin{array}{l}\text { Heating } \\
\text { time in min }\end{array}$ & $\begin{array}{c}\text { Frame rate } \\
\text { in } \mathrm{Hz}\end{array}$ \\
\hline $\begin{array}{l}\text { Delaminations and } \\
\text { varying plaster } \\
\text { thicknesses, plaster on } \\
\text { concrete }\end{array}$ & $\begin{array}{l}\text { Laboratory } \\
\text { (indoor) }\end{array}$ & $\begin{array}{l}\text { Infrared } \\
\text { radiator with } \\
7200 \mathrm{~W}\end{array}$ & 12 & 0.5 \\
\hline $\begin{array}{l}\text { Structural } \\
\text { investigations of } \\
\text { masonry behind plaster }\end{array}$ & $\begin{array}{l}\text { Laboratory } \\
\text { (outdoor) }\end{array}$ & $\begin{array}{l}\text { Fan heater } \\
\text { with } \\
2000 \mathrm{~W}\end{array}$ & 12 & 0.2 \\
\hline $\begin{array}{l}\text { Delaminations on } \\
\text { historic multilayered } \\
\text { sandstone columns }\end{array}$ & $\begin{array}{l}\text { Case study } \\
\text { (indoor) }\end{array}$ & $\begin{array}{l}\text { Fan heater } \\
\text { with } \\
2000 \mathrm{~W}\end{array}$ & 5 & 0.2 \\
\hline
\end{tabular}

\subsection{Plastered concrete specimen}

Figure 3 shows results obtained from investigating a concrete test specimen $\left(1.50 \times 1.50 \times 0.50 \mathrm{~m}^{3}\right)$ covered with plaster with various thickness containing several delaminations between plaster and concrete. The delaminations were simulated by means of punched and unpunched paper-strips of $0.10 \times 0.10$ and $0.20 \times 0.20 \mathrm{~m}^{2}$. The heating time was 1 minute and the recording time 30 minutes. For the experimental set-up see figure 2 and table1.

Alongside the joints figure 3 clearly shows the varying plaster thickness in the colour of the low frequency phase images from thin and light to thick and dark (bottom left: $10 \mathrm{~mm}$, top: $15 \mathrm{~mm}$ and bottom right: $20 \mathrm{~mm}$ ) and vice versa (but not quite as well-defined) in the contrast images. Also apparent is the construction joint in a depth of $10 \mathrm{~mm}$ in the $20 \mathrm{~mm}$ plaster layer in the phase images of higher frequency and the three simulated delaminations in the right part of each image. Only the unpunched paper-strips are visible. 


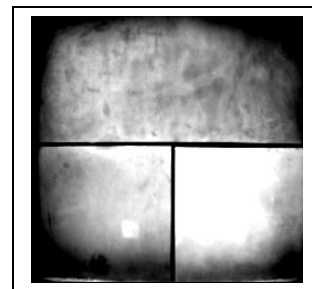

40.0 to $50.0^{\circ} \mathrm{C}$

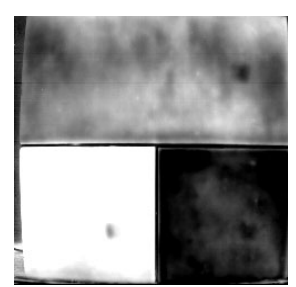

$6.97 \times 10^{-4} \mathrm{~Hz}$

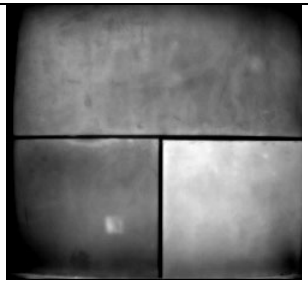

30.0 to $46.0^{\circ} \mathrm{C}$

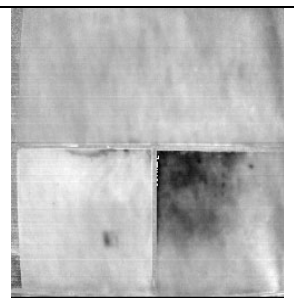

$6.97 \times 10^{-3} \mathrm{~Hz}$

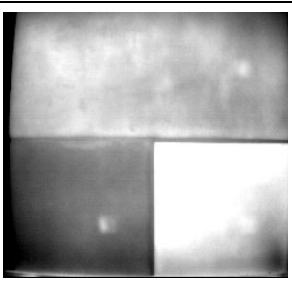

22.0 to $29.0^{\circ} \mathrm{C}$

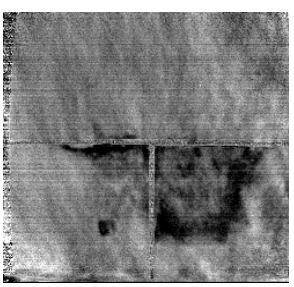

$3.48 \times 10^{-2} \mathrm{~Hz}$

Fig. 3: Contrast images after 12.5 / 125.0 / 625.0 seconds (from left to right) of cooling down time (top) and related phase images at selected frequencies (bottom).

\subsection{Plastered brickwork specimen}

Figure 4 shows results obtained from investigating plastered historical brickwork of a test specimen constructed at BAM in Berlin.

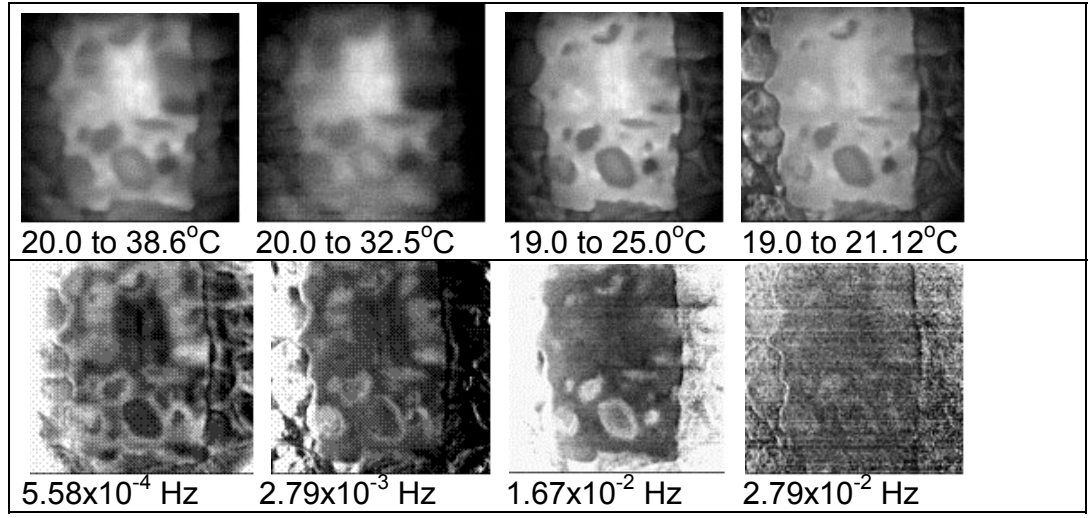

Fig. 4: Contrast images after $0 / 50.0 / 500.0 / 1790.0$ seconds (from left to right) of cooling down (top) and phase images at selected frequencies (bottom) of the plastered natural stonewall.

The measured part of the specimen has a size of $1.0 \times 1.0 \mathrm{~m}^{2}$ and consists of field stones of varying shapes behind plaster of modified thickness $(0.0$ to $3.0 \mathrm{~cm})$. In the upper part and $3.0 \mathrm{~cm}$ behind the surface a brickwork column was implemented. The heating time was 12 and the recording time 30 minutes. For the experimental set-up see figure 2 and table 1. 
The natural stones and, most notably, the structure of the column in the centre of the pictures and the shape of the fieldstones appear more distinct in the phase images. Also the relationship between depth and frequency, at which imperfections appear in the phase images, becomes noticeable. The phase image at low frequency on the left side shows all available information up to half of the thermal penetration depth in one image. With increasing frequency, the available information depth of the phase images decreases.

\subsection{Three layered sandstone columns}

In the frame of the European project ONSITEFORMASONRY sandstone columns in the rotunda of the Altes Museum in Berlin were investigated to locate possible delaminations of the plaster consisting of two different layers (figure 5, left). The first layer belongs to lime plaster having a thickness of 2 to $3 \mathrm{~cm}$. This plaster is the carrying basis for the visible thin stucco marble layer of 3 to $6 \mathrm{~mm}$. Thus three different types of delaminations could be anticipated: delaminations of the stucco marble layer, delaminations of the plaster and a combination of both.

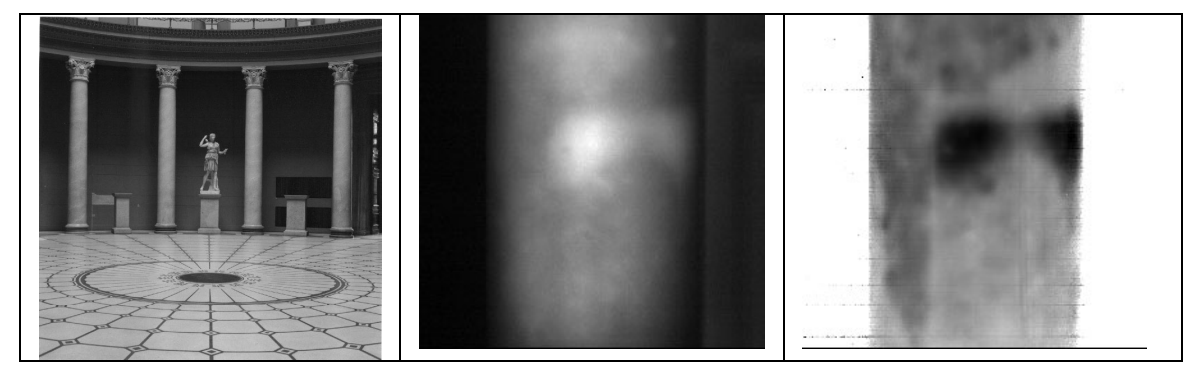

Fig. 5: Stucco-marble columns in the rotunda (left), selected thermal contrast image (middle) and phase image (right) of a chosen column section.

For the heating of the surface of the columns a conventional electric fan heater was used. The heating time was 5 and the recording time 15 minutes. For the experimental set-up compare also table 1 . In contrast to the heating with radiant heaters the convective heating is independent from the different emissivities of the surfaces and the geometries and causes a steady-going rise of temperature at the surface of the object. It was not possible to heat up the complete investigated area in one cycle due to height of the columns $(534 \mathrm{~cm})$. Therefore it was necessary to divide the area in segments and to treat each of the parts individually. Each of the investigated segments of the column has been recorded with individual camera settings. For the processing of the data the segments have been put together according to their original position at the column (indicated through markers on the surface).

Figure 5 shows exemplary results from the investigations carried out. In the middle part of the thermal image (figure 5 middle) gained from IT clearly a hot spot is visible. And in the upper part a second inhomogeneity might be accepted. In the phase image (figure 5 right) the inhomogeneities appear more clearly, the geometry of the assumed delaminations becomes visible, even on the edge of the picture, where the column bends out of sight. At time, it is not possible to decide whether the delaminations are between sandstone and plaster or between plaster and stucco marble. For further quantitative analysis, numerical simulations are planned. 


\section{Conclusions}

PPT is a suitable enhancement for IT measurements in CE. The influence of inhomogeneous surface structures or heating is at least reduced and as it is known for LT the phase images in PPT display deeper voids with higher contrast than temperature or amplitude images. The apparent relationship between depth and frequency, at which imperfections appear in the amplitude and in particular the phase images, is a subject of further research.

\section{Acknowledgements}

The presented research has been funded by the German Research Foundation (Deutsche Forschungsgemeinschaft, DFG) and by the European Commission (Project Acronym: ONSITEFORMASONRY).

\section{REFERENCES}

[1] Wu, D., Wu, C. Y. and Busse, G.: Investigation of resolution in lock-in thermography: theory and experiment, in: Proceedings of QIRT 1996, Pisa: Edizioni ETS, 1997, pp. 269-274.

[2] Brink, A., Maierhofer, C., Röllig, $M$. und Wiggenhauser, $H$.: Auswertungsmethoden der Impuls-Thermografie zur Ortung von Fehlstellen in Betonstrukturen, in: Thermografie-Kolloquium 2001, 22.09.2001, Unversität Stuttgart, DGZfP-Berichtsband auf CD 77, 2001, Vortrag 14

[3] Maldague, X. and Marinetti, S.: Pulse Phase Thermography, J. Appl. Phys. Vol. 79, No. 5, 1996, pp. 2694-2698.

[4] Vavilov, V., Marinetti, S., Grinzato, E. and Bison, P. G.: Thermal tomography, characterization and pulse phase thermography of impact damage in CFRP, SPIE Vol. 3361, 1998, pp. 275-281.

[5] Zweschper Th., Wu D. and Busse G.: Detection of loose rivets in aeroplane components using lockin thermography, in: Quantitative infrared thermography, QIRT 98, Eurotherm Series 60, D. Balageas, G. Busse, and G. M. Carlomagno (Eds.), 1998, pp. 161-166.

[6] Wild, W., Büscher, K. und Wiggenhauser, H.: Amplitude sensitive modulationthermography to measure moisture in building materials, in: Snell, J. R. and Wurzbach, R. N. (Eds.); Proceedings of Thermosense XX, Orlando, 14.-16. April 1998, Bellingham: Proceedings of SPIE, Vol. 3361, 1998, pp. 156-162.

[7] Zwischenbericht zum DFG-Forschungsvorhaben: Struktur- und Feuchteuntersuchungen von Bauteil- und Bauwerksoberflächen mit der ImpulsThermografie, Geschäftszeichen WI 1785/1-1/2 und HI 636/2-1/2, Berlin, 2001 (unveröffentlicht).

[8] Maierhofer, Ch., Brink, A. Röllig, M. und Wiggenhauser, $H$.: Anwendung der Impuls-Thermografie als quantitatives zerstörungsfreies Prüfverfahren im Bauwesen, in: DGZfP-Jahrestagung 06.-08. Mai 2002 in Weimar, DGZfP-Berichtsband BB 80-CD, Vortrag 45, 2002, Berlin.

[9] X. Maldague, F. Galmiche and Ziadi, A.: Advances in pulsed phase thermography, J. Infrared Phys. Technol. 43, 2002, pp. 175-181.

[10] Weritz, F., Wedler, G., Brink, A., Röllig, M., Maierhofer, Ch. and Wiggenhauser, $\mathrm{H}$.: Investigation of concrete structures with Pulse Phase Thermography, in: DGZfP (Ed.); International Symposium Non-Destructive Testing in Civil Engineering (NDT-CE) in Berlin, Germany, September 16-19, 2003, Proceedings on BB 85-CD, V80, 2003, Berlin. 